\title{
Erratum to: Intelligent Systems for Manufacturing
}

Luis M. Camarinha-Matos ${ }^{1}$, Hamideh Afsarmanesh ${ }^{2}$, and Vladimir Marik ${ }^{3}$

1 New University of Lisbon, Lisbon, Portugal

2 University of Amsterdam, Amsterdam, The Netherlands

3 Czech Technical University, Prague, Czech Republic

\section{Erratum to:}

\section{L.M. Camarinha-Matos et al. (Eds.) Intelligent Systems for Manufacturing DOI: $10.1007 / 978-0-387-35390-6$}

The book was inadvertently published with an incorrect name of the copyright holder. The name of the copyright holder for this book is: (c) IFIP International Federation for Information Processing. The book has been updated with the changes. 